\title{
ALCANCE DE LA CULPA COMO TEORÍA DE LA RESPONSABILIDAD DERIVADA DE LA CONDUCCIÓN DE VEHÍCULOS EN COLOMBIA
}

\author{
Yery Luz Sierra Vanegas
}

Para citar este artículo:

Sierra Vanegas, Yery Luz, Alcance de la culpa como teoría de la responsabilidad derivada de la conducción de vehículos en Colombia 


\section{RESUMEN}

Conducir un vehículo es una actividad peligrosa de común ocurrencia que presenta un riesgo, que una vez materializado exige la reparación del daño. En Colombia, la doctrina y la jurisprudencia de la Corte Suprema de Justicia han adoptado diferentes teorías que determinan la responsabilidad derivada de la conducción de vehículos. Entre ellas, la teoría de la culpa (probada o presunta) es la más aceptada. Sin embargo, esta teoría ha recibido muchas críticas desde el análisis económico del derecho. Por ello, en ordenamientos jurídicos avanzados, la responsabilidad para las actividades peligrosas ha pasado de la teoría subjetiva a la objetiva (en particular, a la teoría de la distribución del riesgo), que propende por el resarcimiento total de las víctimas a un bajo costo para el mercado y la sociedad. Este trabajo propone las bases teóricas para que la jurisprudencia de la Corte Suprema de Justicia adopte la teoría de distribución del riesgo.

\section{Palabras clave}

Teoría, Responsabilidad, Actividad Peligrosa, conducción de vehículo. 


\section{ALCANCE DE LA CULPA COMO TEORÍA DE LA RESPONSABILIDAD DERIVADA DE LA CONDUCCIÓN DE VEHÍCULOS EN COLOMBIA}

\section{Contenido}

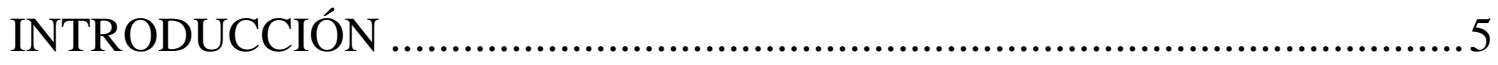

1. SISTEMA DE RESPONSABILIDAD DERIVADA DE LA CONDUCCIÓN DE AUTOMOTORES EN COLOMBIA

1.1 Doctrina aplicable para la actividad peligrosa de la conducción de vehículos en Colombia......................................................................

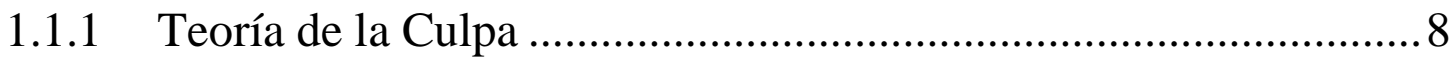

1.1.1.1 Teoría de la presunción de culpa ..............................................9

1.1.1.2 Teoría de la culpa probada....................................................... 10

1.1.1.3 Critica de la teoría de la culpa según Guido Calabresi.............. 10

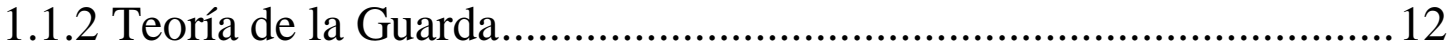

1.1.3 Teoría de la Presunción de Responsabilidad ................................... 13

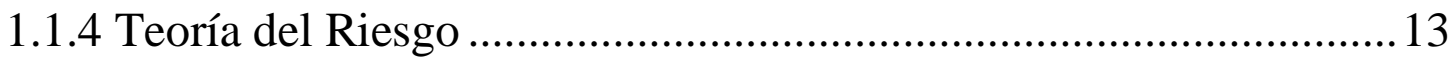

1.2 Tendencia jurisprudencial Corte Suprema de Justicia: La responsabilidad por la conducción de automotores .................................. 15

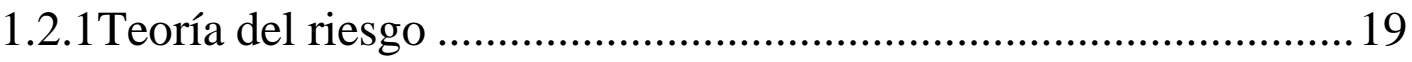

1.2.2 Teoría de la presunción de culpa ..............................................21

1.2.3Teoría de la falla en la Guarda.....................................................23

1.2.4 Teoría de la culpa probada........................................................25

1.2.5 Análisis de la tendencia jurisprudencial, la Corte Suprema de

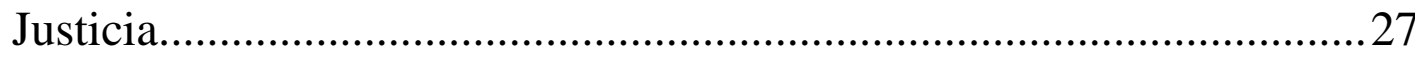


1.3 Teorías que sustentan la actividad peligrosa en otros ordenamientos

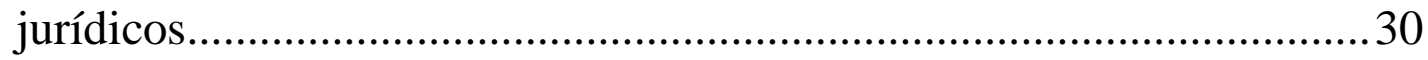

1.3.1 Principios de Derecho Europeo de la Responsabilidad Civil y la Responsabilidad derivada de la conducción de vehículos.

1.3.2 La Actividad Peligrosas de la Conducción y su regulación en el Código Civil Peruano.

2. HACIA UNA NUEVA TEORÍA DE LA RESPONSABILIDAD POR LA ACTIVIDAD PELIGROSA DE LA CONDUCCIÓN DE VEHÍCULOS 34

2.1 El Problema del Costo Social: Teorema de Ronald Harry Coase .......34

2.2 La Teoría de la Distribución del Riesgo ................................................36

2.2.1 Relación entre la teoría de la distribución del riesgo y el teorema

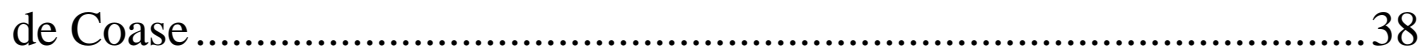

2.2.2 Diferencias entre la teoría de la distribución del riesgo y la teoría

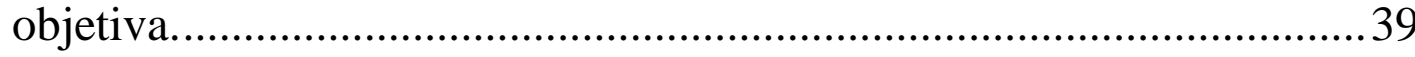

2.2.3 El Seguro obligatorio como medio de difusión del riesgo ............42

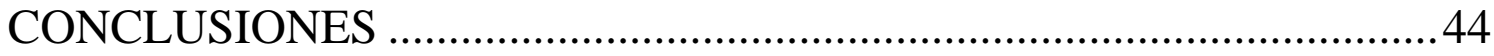

i. Seguimiento crítico de la tendencia jurisprudencial y doctrinal en

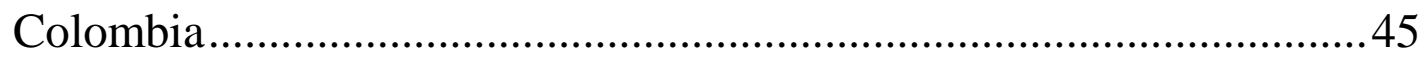

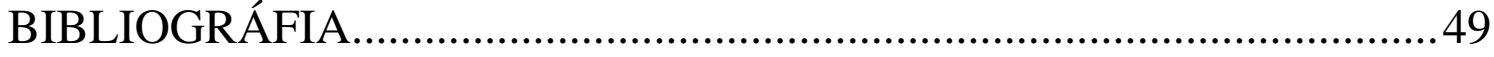




\section{INTRODUCCIÓN}

La teoría de la responsabilidad surge de la necesidad de reparar los daños causados a un individuo, de modo que el antiguo aforismo en el que las cosas se pierden para su dueño, resulta inaceptable cuando el daño es causado por un tercero.

Por lo anterior, es determinante establecer la responsabilidad de los actores en el desarrollo de actividades consideradas como peligrosas, específicamente la conducción de vehículos, actividad para la cual se han planteado diferentes teorías de la responsabilidad. Estas teorías han tratado de garantizar la compensación del daño causado a la víctima, atendiendo a diferentes criterios que serán abordados en este documento.

En este texto se analizarán dichas teorías a lo largo de su evolución legal y jurisprudencial con el fin de resolver el problema de investigación: ¿la teoría de la culpa de corte romanista es adecuada para sustentar la responsabilidad derivada de la actividad riesgosa de conducción de vehículos?

Este interrogante se resolverá mediante el desarrollo del objetivo específico correspondiente al análisis de las teorías de responsabilidad, que será abordado en dos secciones: En la primera, desarrollaremos el sistema de responsabilidad derivada de la conducción de vehículos en Colombia; y en 
la segunda, se planteará la contribución del análisis económico del derecho a la responsabilidad y la teoría de la distribución del riesgo. 


\section{SISTEMA DE RESPONSABILIDAD DERIVADA DE LA CONDUCCIÓN DE AUTOMOTORES EN COLOMBIA}

Desde la doctrina y la jurisprudencia en Colombia se han planteado varias teorías que desarrollan la responsabilidad derivada de la conducción de vehículos.

Por lo tanto, esta sección estará dedicada a una breve descripción dogmática de las teorías (principalmente mediante aportes doctrinales) y al desarrollo de la tendencia jurisprudencial de la sala de casación civil de la Corte Suprema de Justicia aplicable para la actividad peligrosa de la conducción de vehículos en Colombia.

\subsection{Doctrina aplicable para la actividad peligrosa de la conducción de vehículos en Colombia}

La regulación legal de las actividades peligrosas en Colombia, se encuentra contemplada en el artículo 2356 Código Civil, que establece: "Por regla general todo daño imputado a la malicia o negligencia de otra persona, debe ser reparado por esta" (...). Desde este marco normativo la doctrina ha desarrollado teorías para determinar la responsabilidad.

Entre las teorías, se encuentran la teoría basadas en la culpa (presunta y probada), la teoría de la guarda, la teoría de la presunción de la responsabilidad y la teoría del riesgo. 


\subsubsection{Teoría de la Culpa}

La norma de las actividades peligrosas en Colombia "descansa en el cuidado que tomaría una persona razonable en las circunstancias específicas" (Spector, 2003, p.244). Dicha responsabilidad está basada en la culpabilidad del sujeto que causa el daño, cuya conducta será sometida al juicio de reproche de su negligencia (Acedo, 2000).

La responsabilidad subjetiva presupone esencialmente la culpabilidad de su agente, y existe en cuanto el hecho nocivo emane de la culpa o dolo del actor. Para determinar la culpa es necesario analizar la conducta del sujeto (Alessandri, 1943). Así, de la interpretación del artículo 2356 Código Civil, surge que la responsabilidad civil extracontractual prevista en la norma viene impregnada de las tesis subjetivas que entronizan la culpa como principio fundamental de la responsabilidad. (Corte Suprema de Justicia, 2000).

Sin embargo, los fundamentos actuales de responsabilidad basada en la culpa no corresponden al término tradicional ${ }^{1}$, pues quedaron rezagados frente a la evolución de la sociedad. Esto implicó reinterpretar los textos legales basados en la culpa, introduciendo nuevos alcances y consecuencias (Peirano, 2004), tales como la culpa presunta y probada.

\footnotetext{
1“En el concepto puro de la teoría de la culpa, la prueba quedaba siempre a cargo de la víctima, de acuerdo con el principio general de que la prueba de un hecho corresponde al que lo alega" (Peirano, 2004, P 142).
} 


\subsubsection{Teoría de la presunción de culpa}

En el desarrollo de la actividad peligrosa la presunción de culpa ${ }^{2}$ es un postulado más riguroso que en el sistema de culpa tradicional, pues no solo basta acreditar la diligencia debida para desvirtuar la presunción de culpa que pesa sobre el guardián de la cosa o actividad con la que se crea el peligro para los asociados, sino que se deberá acreditar la prueba del factor extraño que incide fundamentalmente en la esfera de la causalidad más que en la culpabilidad (Santos, 2006).

La tesis de la responsabilidad por presunción de culpa en las actividades peligrosas es defendida por Alessandri (1943), quien manifiesta que el legislador presume la culpa para facilitar la prueba de la víctima, la que solo deberá acreditar los hechos de los que proviene la presunción mientras que el sujeto sobre el cual recae la presunción deberá probar que actuó con diligencia y que el daño provino de causa extraña. Coincidiendo, Martínez (1998) asegura que el Código Civil contempla la presunción de culpa, en el caso de la responsabilidad por actos de terceros, donde el presunto culpable deberá desvirtuar la presunción de culpa, con la prueba de la diligencia.

${ }^{2}$ El postulado de presunción de culpa invierte la carga de la prueba en el ofensor, a diferencia de la noción tradicional de culpa en el que la carga de la prueba corresponde a la víctima. 


\subsubsection{Teoría de la culpa probada}

En principio, la culpa probada consiste en ejecutar una actividad que, aunque lícita, crea más peligros de los que la sociedad está en capacidad de soportar Jaramillo (2013). Para Javier Tamayo Jaramillo (2013) la naturaleza de la responsabilidad por actividades peligrosas, descansa en la culpa probada. De modo que realizar una actividad peligrosa implica en sí misma la imprudencia susceptible de culpa para efectos de la responsabilidad. En otras palabras, realizar la actividad peligrosa implica que el causante ya incurrió en culpa y que, por la sola acción, la culpa queda probada.

Para el autor, la culpa presunta y la responsabilidad presunta no son los fundamentos de la responsabilidad por actividades peligrosas. La primera porque puede desvirtuarse con la prueba de la ausencia de culpa y la segunda, teniendo en cuenta que antes de la realización del perjuicio, la culpa ya existía. De allí que la teoría de las presunciones no sea de recibo para el autor (Tamayo, 2013).

\subsubsection{Critica de la teoría de la culpa según Guido Calabresi}

En esta sección resultan muy importantes las objeciones realizadas por Guido Calabresi a la teoría de la responsabilidad por culpa. Para Guido Calabresi (1984) la responsabilidad por culpa es un sistema muy costoso e inadecuado para determinar la responsabilidad en el mundo actual porque: 
i). se funda en la búsqueda del culpable y posteriormente en la reparación de víctima; y ii). no indaga entre los sujetos involucrados quién ostenta la mejor posición de conocer el riesgo o está mejor informado del costo de evitar el accidente y fraccionar los daños.

i. El sistema de responsabilidad por culpa no podría ser empleado si pretendemos establecer el óptimo control del costo de los accidentes automovilísticos en el mercado. Debido a que la insuficiente o nula división de los daños y la delación de los mismos a la víctima ante la inexistencia de culpa, la teoría de la culpa evita que se obtenga el resarcimiento adecuado de los daños, generando costos que podrían ser evitados (Calabresi, 1984).

ii. Asevera Calabresi (1984) que el hecho de que el fundamento de culpa sea la víctima y el ofensor es inoperante en la actualidad teniendo en cuenta que los accidentes no son problemas que afecten solo al culpable y al lesionado, sino a la sociedad en general. Así, un régimen de responsabilidad extracontractual en el que impera la noción de negligencia es muy costoso de operar y está resignado a no conceder reparación en muchos casos, e incluso en algunos asigna compensaciones incompletas a pesar de haber sido impuesta la responsabilidad (Posner, s.f.). Tal como ocurre en los casos de concurrencias de culpa, o en los que existiendo daño, las partes están exentas de culpa, la teoría de la culpa no se ocupa de conocer el sujeto que realmente paga el perjuicio Calabresi (1984). 
En consecuencia, en el sistema de culpa solo se responde "cuando se viola una estructura de cuidado, descuidando a la víctima del daño, imponiendo la carga de soportar las consecuencias de las acciones de otro" (Rosenkrantz, 2006, p293). Por esta razón, el sistema de culpa deja sin compensación a unas víctimas, indemniza demasiado a otras y resuelve los casos con tanta dilación que crea una nueva fuente de costos (Calabresi, 1984).

El fin de la responsabilidad civil es evitar y disminuir los costos de los accidentes (Calabresi, 1984), fines que a través de la culpa difícilmente podrán ser se alcanzados puesto que en la "negligencia, los agentes no tendrán incentivos para incorporar dentro de sus medidas la reducción de actividad". (Papayannis, 2009, p.469).

\subsubsection{Teoría de la Guarda}

Tamayo Lombana (2005) considera que el régimen jurídico colombiano para las actividades peligrosas es la culpa presunta y, además, es aplicable la responsabilidad del guardián. La enumeración del artículo 2356, supone objetos que se ponen en actividad, y corresponde al guarda de la cosa la facultad de uso, dirección control y vigilancia de la actividad, a fin que ésta no ocasione daños, so pena de incurrir en responsabilidad.

Por su parte Tamayo Jaramillo (2013) indica que la teoría de la guarda solo se aplica a la responsabilidad de la empresa transportadora derivada del accidente de tránsito de alguno de los vehículos a su cargo. 


\subsubsection{Teoría de la Presunción de Responsabilidad}

Para Velásquez (2015) el fundamento de la responsabilidad por actividades peligrosas en Colombia es la presunción de responsabilidad, la que define como aquella en la que la predomina la culpa, pero al demandado solo le queda como defensa la prueba de la causa extraña.

El artículo 2356 del Código Civil colombiano consagra la presunción de la responsabilidad, en la que no se requiere el elemento subjetivo de la culpa y se presume el nexo de causalidad, del cual puede librarse el presunto responsable probando, las circunstancias que rompan el nexo causal (Martínez, 1998).

Es preciso aclarar que la presunción de culpa y la de responsabilidad, son diferenciadas por un sector de la doctrina pues, en la culpa presunta concurre la "presunción del elemento subjetivo que el causante puede destruir si acredita haber actuado con diligencia (...). Y por presunción de responsabilidad, cuando el causante no puede exonerarse de la obligación sino probando una circunstancia que destruya el nexo causal" (Martínez, 1998, p.135).

\subsubsection{Teoría del Riesgo}

"Los autores que defienden la teoría del riego manifiestan que quien se aprovecha de un riesgo, quien lo crea, debe indemnizar los daños que de él se deriven"(Tamayo, 2013, p866). Esta teoría de la responsabilidad civil 
prescinde de la conducta del sujeto y por lo tanto del concepto de culpa. El planteamiento principal de esta teoría es promover a través de la reparación un medio de restablecer el equilibrio económico (Peirano, 2004).

El objetivo del derecho de daños es instaurar una norma cuyo propósito sea imputar el riesgo y las pérdidas al sujeto que tenga la mejor condición de fraccionarlos (Calabresi, 1984). A este propósito la responsabilidad objetiva es la más adecuada, para determinar quién ostenta la mejor posición para evaluar si el valor de evitar el daño, excede los costos previsibles de los perjuicios, haciendo responsable a quien está en mejores condiciones de optimizar los costos y obtener una disminución en la suma de los gastos necesario para evitar un accidente (Calabresi \& Hirschoff, 2002).

De manera que, en el criterio objetivo para lograr la reparación, solo basta la relación entre la acción y el daño, presupuestos que permiten a la víctima transferir el costo económico del detrimento al generador del riesgo, obviando el análisis del comportamiento diligente o negligente del agente.

Teniendo en cuenta lo anterior, es preciso abordar la tendencia jurisprudencial que ha desarrollado la Corte Suprema de Justicia para la responsabilidad derivada de la actividad peligrosa, especialmente de la conducción de vehículos. 


\subsection{Tendencia jurisprudencial Corte Suprema de Justicia: La responsabilidad por la conducción de automotores}

La construcción de la tendencia jurisprudencial tiene como fin identificar cuál es la postura mayoritaria de la Corte Suprema de Justicia, en cuanto a la teoría de la responsabilidad derivada de la conducción de vehículos. Esto permitirá dilucidar los cambios de criterio jurisprudencial en cuanto a la teoría de la responsabilidad aplicada en Colombia.

La metodología usada en la elaboración de la tendencia jurisprudencial, es inspirada en la técnica desarrollada por Diego López Medina, en su texto El Derecho de los Jueces ${ }^{3}$. No obstante, no observa de manera estricta los

\footnotetext{
${ }^{33}$ Para López (2006), en la construcción de una de línea jurisprudencial, es necesario establecer el escenario constitucional, las sentencias más relevantes y la construcción teórica de la relación entre los pronunciamientos jurisprudenciales. A efectos de la selección de providencias, López explica que las sentencias se clasifican en no importantes e importantes. En este último grupo, se encuentran las sentencias fundadoras, modificadoras y consolidadoras de línea, a las cuales se llega a partir del punto arquimédico ${ }^{3}$.

Para López (2006) las sentencias fundadoras de línea son: sentencias ambiciosas en materia doctrinaria, se apoyan en el vacío jurisprudencial existente, para consagrar visiones reformistas sin vocación de permanencia en la jurisprudencia. Las sentencias modificadoras son, las que introducen cambios fuertes de jurisprudencia dentro de la línea y las sentencia consolidadora, son aquellas, en las que se aplica un principio contenido en una sentencia anterior (p.164-166). Además, asevera el autor que, siendo la línea jurisprudencial un problema jurídico, debe ser graficado bajo un esquema en el cual la pregunta problema planteada se situé en el centro y a los lados se indiquen las respuestas extremas que la jurisprudencia ha dado al problema (López, 2006).
} 
conceptos desarrollados por López en la construcción de una línea jurisprudencial ${ }^{4}$.

En efecto, en el desarrollo de la tendencia jurisprudencial de la responsabilidad por la conducción de automotores de la Corte Suprema de Justicia, no es posible aplicar de manera íntegra el método propuesto por López por cuanto, en el desarrollo del mismo, no se establecen escenarios constitucionales de protección. Tan solo se elabora la reconstrucción conceptual de las teorías de la responsabilidad derivada de la conducción de vehículos adoptadas por la Corte Suprema. Lo anterior no obsta para reconocer que el esquema desarrollado en este aparte se guió en la técnica de clasificación de sentencias y de graficación de la línea jurisprudencial de López Medina.

De manera que, aplicando la técnica de clasificación de sentencia, se inició la búsqueda en la relatoría de la Corte Suprema de Justicia, en cual se encuentran innumerables providencias que abordan la figura jurídica de la responsabilidad. Sin embargo, este estudio se limitó a la revisión de las sentencias proferidas por la sala civil de la Corte Suprema, en las cuales los hechos correspondían a determinar la responsabilidad civil extracontractual en accidentes de tránsito.

\footnotetext{
${ }^{4}$ El método utilizado en la elaboración de la tendencia jurisprudencial de la Corte Suprema de Justicia, no corresponde al método de Diego López, más aún, cuando el autor plantea este método solo para el estudio de las decisiones adoptadas por la Corte Constitucional. Sin embargo, en la elaboración de la tendencia jurisprudencial, se adoptan algunos conceptos desarrollados por Diego López en la construcción de una Línea Jurisprudencial.
} 
Así, la reconstrucción conceptual, se apoya en la identificación de las sentencias más relevantes, ${ }^{5}$ proceso inició con el estudio de la sentencia más reciente, que aborda la responsabilidad por la actividad peligrosa de la conducción. En este caso con las sentencias del 6 de mayo 2016, providencia que en el método de López se denomina punto arquimédico o de apoyo.

Ahora bien, dentro de las sentencias relevantes, se encuentra la decisión más antigua, la más citada, la providencia inicial o fundadora del estudio de la responsabilidad por la actividad peligrosa de la conducción, que corresponde a la sentencia del 14 de mayo de 1938. En esta operación, se identifican también, las providencias en las que la Corte Suprema cambió su posición en cuanto a la teoría la responsabilidad aplicada en el caso de accidente de tránsito. De modo que la Corte Suprema de Justicia introduce, con las sentencias de 31 de mayo de 1938, de 18 de mayo de 1972 y la del 1 de junio de 2010, diferentes teorías, modificando su posición respecto al supuesto de responsabilidad.

Una vez conformado el registro de las sentencias, se procedió a organizarlas acuerdo la teoría de la responsabilidad que desarrollara cada sentencia. De esta manera, se construyeron conjuntos de sentencias que desarrollaran la teoría del riesgo - objetiva, la teoría de la guarda y la teoría de la culpa. De estos conjuntos de providencias, se escogieron aquellas que mayor

\footnotetext{
${ }^{5}$ Lassentencias más relevantes, corresponden aquellas que Diego López Medina denomina sentencias
} importantes. 
describen e introducen modificaciones en los planteamientos de las distintas teorías de responsabilidad derivada de la conducción de vehículos. Este último grupo de sentencias corresponde a los fallos desarrollados en el texto.

Teniendo en cuenta lo anterior, se elaboró y graficó la reconstrucción conceptual de la tendencia de la Corte Suprema de Justicia, para determinar la responsabilidad derivada de las actividades peligrosas originadas de la conducción.

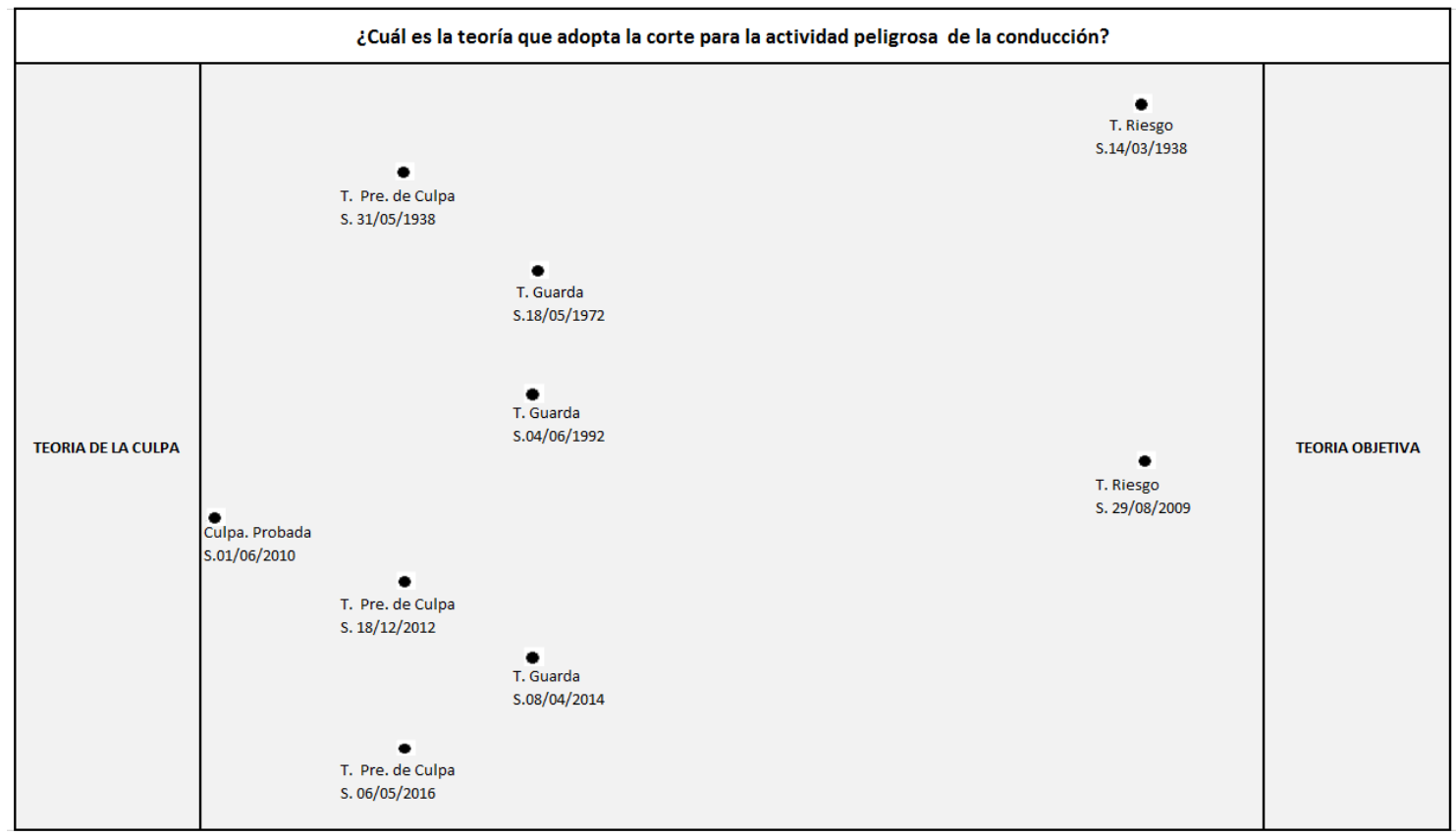

Fuente propia. Basada en el modelo de López Medina (2006) 
Este esquema se elaboró así: En la parte superior del grafico se introdujo la pregunta problema y en los extremos posiciones opuestas ha explicado la Corte Suprema de Justicia y en el interior del cuadro se ubicaron las sentencias adoptadas por la Corte, atendiendo al orden cronológico y a los patrones de cambio decisional en el que se adoptaron las teorías, describiendo la dinámica de la decisión.

En sentencia del 14 de mayo de 1938 la Corte Suprema de Justicia acoge la teoría del riesgo, Sin embargo, además de esta teoría, la Corte desarrolla otras como la presunción de culpa, la culpa probada, la responsabilidad del guarda, como se pasa a exponer. Es preciso aclara que las teorías relacionadas en el gráfico, no se abordan en el orden expuesto en la sección anterior, pues la construcción de la tendencia jurisprudencial observa la disposición cronológica en la que Corte Constitucional desarrolló cada teoría.

\subsubsection{Teoría del riesgo}

Esta teoría es desarrollada por la Corte Suprema de Justicia en la primera sentencia que estudio la responsabilidad originada de accidentes, la sentencia de fecha 14 de mayo de 1938, con ponencia del magistrado Ricardo Hinestroza Daza, y se retomó setenta años después en la sentencia de fecha 29 de agosto de 2009 del magistrado William Namen Vargas. 
Caso Rosendo Echeverri y Lucrecia Botero vs Pablo Villegas - Sentencia 14 de mayo de 1938:

El escenario de protección se sitúa en un accidente de tránsito en cual el hijo de los demandantes cae al suelo, cuando se movilizaba en una bicicleta y es arrollado por un vehículo que conducía el señor Villegas hecho que le causa la muerte.

En este contexto, la Corte analiza la responsabilidad del conductor del automotor, y establece que para el desarrollo de las actividades previstas en el artículo 2356 del código civil, se aplica la teoría del riesgo, en la que se invierte la carga de la prueba, por lo que, se presumen los daños causados por el responsable quien crea el riesgo y solo podrá ser exonerado demostrando caso fortuito, fuerza mayor o intervención de elemento extraño.

Caso José Absalón y Gerardo Zuluaga vs Bavaria S.A - Sentencia de 24 de agostos del año 2009.

En este caso, los demandantes solicitan declarar la responsabilidad de la demandada; por los daños ocasionados por el accidente, en el que el vehículo TKA 271 fue colisionado por el Bus 835 de la demandada. En este último el conductor, invadió el carril por donde circulaba el automotor TKA 271, esta acción originó un choque que causó múltiples daños al vehículo del demandante. 
La Corte Suprema de Justicia manifiesta que, el régimen de responsabilidad por actividades peligrosas "es el riesgo que el ejercicio de una actividad peligrosa comporta por el peligro potencial e inminente de causar un daño a los bienes e intereses tutelados por el ordenamiento".

\subsubsection{Teoría de la presunción de culpa}

La teoría de la presunción de la culpa, es el criterio mayormente acogido por la Corte Suprema de Justicia desde la sentencia del 31 de mayo de 1938. Para los escenarios de protección en los cuales se ven involucrados un automotor y un peatón o dos vehículos en movimiento.

Caso hermanas Bustamante vs. The Santa Marta Railway $\mathrm{C}^{\circ}$ Limited sentencia del 31 de mayo de 1938

Las demandantes en calidad de hijas Antonio Bustamante, solicitan sean indemnizadas por los daños y perjuicios sufridos por la muerte de su padre, ocasionada por el atropello de un motor de la empresa.

En este caso la Corte Suprema de Justicia, realiza un análisis del artículo 2356 y establece que para el caso específico que:

La carga de la prueba no corresponde al damnificado, sino que corre de cargo del agente negligente imprevisto y descuidado, que por malicia o negligencia causó el daño (...) De aquí nace la moderna teoría de la presunción de culpa, según la cual el agente de la actividad peligrosa se presume responsable de sus consecuencias, habida consideración a los daños que de su natural actividad puedan originarse. 
Caso Familia Valencia Lozano y Lozano Sánchez vs Empresa de Buses Blanco y Negro - Sentencia del 18 de diciembre del 2012

En este caso los demandantes solicitan se declare la responsabilidad del demando, porque la buseta de placa VBU-302 llevaba la puerta abierta mientras estaba en movimiento, lo que originó que la señora Lozano Sánchez cayera al suelo causándole la muerte.

En este fallo la Corte Suprema de Justicia, cita las sentencias del 10 de agosto del 1941, del 16 de marzo de 1945 y la del 28 de Julio de 1970 y manifiesta que "la jurisprudencia de esta Corte ha sostenido de manera constante e inveterada que ella consagra una presunción de culpa en contra del demandado, quien solo puede exonerarse de responsabilidad si demuestra que el hecho se produjo por una causa extraña"

Familia Toscano Beltrán vs Cooperativa de Transportadores Cúcuta Limitada- Sentencia 6 de mayo 2016

Diana Carolina Beltrán Toscano se movilizaba en una motocicleta, sin casco, ni chaleco reflector, a su vez no porta póliza de seguro, y chocó con un automotor de servicio público, el cual generó graves lesiones a la motociclista.

La Corte Suprema de Justicia, indica que "Tratándose de accidente de tránsito producido por la colisión de dos automotores, cuando concurren a la realización del daño, la jurisprudencia ha postulado que estando ambos 
en movimiento, estarían mediados bajo la órbita de la presunción de culpas".

\subsubsection{Teoría de la falla en la Guarda}

La teoría de la guarda también es acogida por la Corte Suprema de Justicia, particularmente en los casos en los que se debate la responsabilidad de las empresas propietarias de vehículos que sufre un accidente de tránsito del cual se derivan daños a terceros. De esta responsabilidad solo se podrán exonerar demostrando la ausencia de la tenencia sea en virtud de un negocio jurídico o un hurto.

Caso Nicasio Díaz, Braulio Fino, José Amaya, Ana Solano vs. Aceites Vegetales Refinados Ltd. -Sentencia del 18 de mayo de 1972

Los hechos que rodean la demanda hacen referencia a que el camión D9814 ocasionó un accidente, mientras era conducido por un empleado de la empresa Aceites Vegetales Refinados (propietaria del vehículo). Por tal hecho los demandantes solicitan se declare la responsabilidad de la empresa y se pague indemnización respectiva.

En esta ocasión, la Corte Suprema de Justicia introduce la responsabilidad por el hecho de otro, fundamentado en la teoría de la falta en la guarda. Indica la Corte que la presunción de culpa por actividades peligrosas no excluye la responsabilidad por el hecho ajeno, "la presunción de 
culpabilidad en contra quien ejercita una actividad peligrosa afecta (...) al empleador, dueño de la empresa o de la cosa causante del daño". Por lo tanto "la responsabilidad del dueño por el hecho de las cosas inanimadas proviene de la calidad de guardián (...), es decir por quien tiene sobre las cosas el poder de mando, dirección y control". En este caso la empresa es responsable debido a tiene a su cargo la dirección de la actividad peligrosa a través de su empleado.

Caso Hermanos Rosensvaig, vs. Mercados y Almacenamientos $\underline{\text { Tequendama Limitada- Sentencia del } 04 \text { de junio de } 1992}$

Los demandantes solicitan que se declare la responsabilidad de la entidad demanda, teniendo en cuenta los siguientes hechos: señor Rigoberto Duarte empleado conducía la camioneta de Placas EW-4476 de propiedad de la entidad demandada, cuando se subió a la acera y atropelló a Edgar Upequi y a Cecilia Rosensvaig, evento que causó la muerte de Cecilia Rosensvaig y le ocasionó que Edgar Upegui perdiera un brazo.

En este caso la Corte Suprema resalta que en el "concepto de "guardián" de la actividad será entonces responsable la persona física o moral que, al momento del percance, tuviere sobre el instrumento generador del daño un poder efectivo e independiente de dirección, gobierno o control, sea o no dueño, y siempre que en virtud de alguna circunstancia de hecho no se encontrare imposibilitado para ejercitar ese poder". 
Caso María Lascano Cifuentes, Gilberto Peña Nur y Juan Fernando Peña Lascano vs. Pan American de Colombia Compañía de Seguros S.A. y Camilo Rodríguez Amador- Sentencia del 8 de abril 2014

En este fallo se analizan los siguientes hechos: la Aseguradora Pan American de Colombia Compañía de Seguros S.A., propietaria de un vehículo suscribe con Mauricio Rodríguez un convenio de asignación, (contrato por medio del cual la empresa aseguradora entrega al asignatario la tenencia del automotor). Estando el vehículo en tenencia de Mauricio Rodríguez y mientras era conducido por Camilo Rodríguez (hijo del asignatario), el automotor se choca con un camión y le causa la muerte de una niña.

$\mathrm{Al}$ analizar la responsabilidad de la compañía aseguradora, del asignatario y del conductor del vehículo, la Corte Suprema de Justicia manifiesta que en el caso se configura la guarda compartida, por lo que indica que es posible “imputar a varios sujetos la responsabilidad en la realización del daño, producto de una actividad riesgosa, porque de una u otra forma ejercen, todos ellos, control y dirección efectiva sobre la actividad”. Así, a pesar de que la empresa de seguros mediante contrato entregó la tenencia del vehículo al asignatario, ello no la libra de la responsabilidad por la guarda compartida en la actividad.

\subsubsection{Teoría de la culpa probada}

Para el caso de la responsabilidad derivada de la conducción de vehículos, la Corte Suprema de Justicia muy poco desarrolla la teoría de la culpa 
probada, teniendo en cuenta que esta corresponde al desarrollo del artículo 2341 del Código Civil. Sin embargo, en la sentencia 01 de junio de 2010 la Corte Suprema, al analizar un caso de actividades peligrosas concurrentes indica que opera la culpa probada.

Juan Diego Arias Galvis Vs Margarita María Ramírez Jaramillo, Litografía Berna S. A.y Royal \& Sun Alliance Seguros Colombia - Sentencia 1de junio $\underline{\text { de } 2010}$

Las circunstancias fácticas que rodean el litigio responden, a un accidente de tránsito que tuvo lugar cuando el demandante y los demandados ejercían de manera simultánea actividades peligrosas, la señora Jaramillo se movilizaba en un vehículo y el demandante en una motocicleta.

En el análisis de este caso, la Corte Suprema de Justicia manifestó"en materia de responsabilidad civil por actividades peligrosas concurrentes, ciertamente la jurisprudencia de esta Corporación ha estimado que ella debe estar sujeta a un régimen particular -eliminación de las presunciones de culpa para pasar a un régimen de culpa probada."

Este fallo fue citado en la sentencia de tutela resuelta por la Corte Suprema de Justicia el 18 de febrero de (2016). En la que se debatió el derecho al debido proceso, dentro de un trámite ordinario de responsabilidad civil extracontractual derivada de un accidente de tránsito en el que un vehículo de servicio público y un motociclista que murió en el accidente.

El anterior ejercicio de construcción de la tendencia jurisprudencial de la Corte Suprema, se perfecciona, con el análisis de la evolución de las teorías 
y la tendencia o patrón decisional adoptado por la Corte Suprema de Justicia, para resolver los casos en los cuales se debate la responsabilidad derivada de la conducción.

\subsubsection{Análisis de la tendencia jurisprudencial, la Corte Suprema de Justicia}

Tal como se puede apreciar en el gráfico de la tendencia jurisprudencial, la Corte Suprema de Justicia no tiene posición determinada y constante en la que haya establecido una teoría aplicable, para determinar la responsabilidad derivada de la conducción de vehículos. No obstante, este ejercicio nos permite hacer un análisis y anotaciones importantes:

i. Aunque no exista una teoría determinada la Corte Suprema sostiene una tesis mayoritaria en la culpa presunta. No obstante, la culpa presunta no es desarrollada bajo los fundamentos de culpa si no de la responsabilidad objetiva.

ii. La Corte Suprema inició el análisis de la responsabilidad derivada de la conducción de vehículo, desde la teoría del riesgo que mutó y sirvió de fundamento para la construcción de la teoría de la culpa presunta. Es por eso que, para la Corte, la única eximente de responsabilidad en la culpa presunta es la causa extraña y no la prueba de negligencia. En este sentido, manifiesta Velásquez que la Corte Suprema de Justicia, en el desarrollo de la responsabilidad por actividad peligrosa no valora el elemento 
culpa, empero alude a la presunción de culpa, indicando que hay lugar a su exoneración con la causa extraña y no mediante la diligencia (Velásquez, 2013).Esto origina que la Corte Suprema dé un tratamiento erróneo a la culpa presunta pues la reviste de objetividad al cambiar la diligencia por la ruptura del nexo causal.

iii. En la construcción de la tendencia se identifica que la Corte Suprema de Justicia, confunde los términos de presunción de responsabilidad y presunción de culpa. Estas figuras jurídicas son diferentes pues en una se presume la negligencia y en otra la responsabilidad de actor. En la sentencia del 31 de mayo del 1938, la Corte Suprema manifiesta que en "la presunción de culpa, el agente de la actividad peligrosa se presume responsable”. En esta sentencia, la Corte iguala conceptos distintos, situación que es observada por Aramburo (2008), quien indica que "(e)n Colombia, el hecho de que la legislación civil consagre un sistema cuya regla es la culpa, sin tener un régimen general para las actividades propias de la sociedad de riesgo, suele llevar a confusiones conceptuales" (P.33).

iv. Cuando en un accidente de tránsito esté involucrado un vehículo de propiedad de una empresa o el propietario es distinto al agente que ocasionó el hecho dañino, la Corte manifiesta que la teoría aplicable es la falla en la guarda.La Corte Suprema manifiesta en 
cuanto a la teoría de la guarda que estay la teoría de la culpa presunta no se excluyen.

v. En el caso de concurrencia de actividades peligrosas, la Corte Suprema de Justicia, en la sentencia de $1^{\circ}$ de junio de 2010, abordó el tema desde la teoría de culpa probada. No obstante, la Corte en sentencias anteriores, (Sentencias 27/02/1998 y 06/05/1998) había aclarado que, en los casos de concurrencia de actividades peligrosas, opera la concurrencia de culpas contemplada en el artículo 2357 del código civil. En este sentido, la Corte no define una posición clara frente a la teoría aplicada en la materia.

vi. Con la sentencia de 29 de agosto de 2009, la Corte Suprema intentó establecer teoría objetiva para determinar la responsabilidad en la actividad de la conducción. No obstante, en el año 2012, los argumentos de esta sentencia fueron rebatidos. Una de las razones para no acoger la teoría del riesgo que cabe resaltar es que la Corte manifiesta que, como el artículo 2356 menciona la negligencia, no le es dable a la jurisprudencia salir de ese contexto.

Esta posición de la Corte es censurable teniendo en cuenta, el avance hacia la objetivación en las actividades peligrosas que han adelantado otros ordenamientos jurídicos. En efecto, Mantilla 
indica que es reprochable que la Corte Suprema de Justicia adopte como culposa las actividades peligrosas, solo para hacerlas entrar en el supuesto normativo, contradiciendo ampliamente la realidad y generando ambivalencia en las motivaciones de los fallos judiciales. Igualmente, supone la proliferación de teorías confusas para tratar de explicar cómo culposa a una actividad que, por su sola naturaleza, no lo es. (Mantilla, 2004).

\subsection{Teorías que sustentan la actividad peligrosa en otros ordenamientos jurídicos}

A pesar que la pregunta de investigación se enmarca en el alcance de la culpa como teoría de la responsabilidad derivada de la conducción de vehículos en Colombia, es pertinente esbozar de la teoría de la responsabilidad adoptada para la actividad peligrosa de la conducción de vehículos en los Principios de Derecho Europeo de la Responsabilidad Civil y en el Código Civil Peruano.

Lo anterior, por cuanto estamos ante un tema sobre el cual, si queremos aportar al conocimiento científico, debemos reflexionar a la luz de los aportes del derecho comparado, considerando que las reglas de la responsabilidad civil superan las fronteras.

Se escogieron para este ejercicio de comparación; (1) los Principios de Derecho Europeos de la Responsabilidad Civil y (2) el Código Civil peruano. El primero teniendo en cuenta que son el producto del "trabajo de más de diez años del Grupo Europeo de Responsabilidad Civil, integrado 
por prestigiosos expertos en el estudio de la responsabilidad civil, procedentes de Europa, de la República de Sudáfrica, Israel y los Estados Unidos de América" (Salas, 2013, p.9) y segundo, ser el referente latinoamericano de la regulación en la materia.

\subsubsection{Principios de Derecho Europeo de la Responsabilidad Civil y la responsabilidad derivada de la conducción de vehículos}

Los Principios de Derecho Europeo de la Responsabilidad Civil "incluyen una cláusula general, que abarca todo el campo de la responsabilidad objetiva" (Koch, 2003, p10).Estos principios contemplan la responsabilidad objetiva como el fundamento de las actividades anormalmente peligrosas.

El artículo 5:101 indica los requisitos que debe contener la actividad para ser considerada anormalmente peligrosa. Así, son consideras anormalmente peligrosas aquellas actividades que, no siendo comunes, crean un riesgo de daño, incluso aunque se emplee mucho cuidado en su ejercicio (Art. 5:101).

La disposición anterior solo opera cuando no existe regulación interna específica, pues el artículo 5:102 prevé como otros supuestos de responsabilidad objetiva, los adoptados en las leyes nacionales, como es el caso de la conducción de vehículos. "Por ejemplo, en Francia, el criterio interpretativo del art. $1384 \mathrm{CC}$ seguido por la jurisprudencia, es la responsabilidad objetiva la que no para de avanzar posiciones, en detrimento de la responsabilidad por culpa”. (Martín, 2005, p.17) 
La tendencia a la responsabilidad objetiva expresada en los Principios Europeos de la Responsabilidad se materializa no solo en la actividad anormalmente peligrosa, sino en todos los supuestos de responsabilidad objetiva establecidos en las normas internas de los países. Inclusive el artículo 5:102 permite que los supuestos de responsabilidad objetiva puedan establecerse por analogía cuando determinada acción origine un riesgo parecido. De manera que, como lo establece Koch (2003) "la evaluación del comportamiento del causante del daño pierde gradualmente relevancia cuanto mayor es el riesgo que la actividad entraña (p.8).

\subsubsection{La actividad peligrosa de la conducción y su regulación en el Código Civil Peruano}

El Decreto Legislativo No 295del 1984 (Código Civil de Perú), establece la responsabilidad por la actividad peligrosa, desarrollada en el artículo1970, el cual dispone: "Aquel que, mediante un bien riesgoso o peligroso, o por el ejercicio de una actividad riesgosa o peligrosa, causa un daño a otro, está obligada a repararlo" (art. 1970).

Al respecto Taborda (2000) indica que "una actividad se considera riesgosa cuando su "realización normal y cotidiana suponga un riesgo adicional al común y ordinario para todos los demás, como sucede con los automotores" 
(p90). Así, en este tipo de actividades, no se indaga por el concepto de culpa, el cual es totalmente intrascendente.

Por lo tanto, el Código Civil de Perú de 1984, a diferencia del Código Civil colombiano, consagra el sistema objetivo de responsabilidad para el ejercicio de la conducción de vehículos.

Considerado lo anterior, puede observarse cómo la tendencia en el derecho comparado moderno respecto a las actividades peligrosas, en nuestro caso la conducción de vehículos, es de alejarse y obviar el sistema de responsabilidad basado en la culpa. 


\section{HACIA UNA NUEVA TEORÍA DE LA RESPONSABILIDAD POR LA ACTIVIDAD PELIGROSA DE LA CONDUCCIÓN DE VEHÍCULOS}

Además de las tesis tradicionales de la responsabilidad por la actividad peligrosa de la conducción de vehículos, en el mundo jurídico se han desarrollado otras teorías, que permiten analizar el tema desde otros escenarios distintos a la culpa, tal como lo es la teoría de la distribución del riesgo. Este planteamiento, relacionado con la eventualidad que implica un perjuicio y la obligación de indemnizar a otro la configuración del daño, hacen estrecha la relación entre responsabilidad y seguro (Corral, 2004). Este postulado, podría contribuir a la construcción de la teoría de responsabilidad para la actividad peligrosa de la conducción de vehículos en Colombia.

\subsection{El Problema del Costo Social: Teorema de Ronald Harry Coase}

Coase en su texto denominado "El Problema del Costo Social" resalta que la importancia del derecho en la economía radica, en lograr el menor costo de las transacciones del mercado. En este sentido, manifiesta Coase (1960), "informar a la gente que deseamos intercambiar y en qué términos, conducir

negociaciones que lleven a un convenio, redactar el contrato (...). Son operaciones muy costosas; suficientemente costosas para evitar muchas transacciones" (p.98). Para Ronald Coase, el derecho eficiente es aquel, que 
minimiza los costos de las transacciones y permite que en el mercado se ejecuten un mayor número.

Según Coase, el ordenamiento y la limitación de los derechos legales a través de la regulación gubernamental impactan la eficiencia del sistema económico puesto, que puede ocasionar un aumento o disminución del valor de la producción. Para el autor, la industria siempre debe crecer y es razonable aceptar alguna incomodidad suficiente, en pro del bienestar general $(1960)^{6}$. Por esta razón, es importante ponderar entre la utilidad y el daño producido, para decidir si el efecto de la ejecución de la actividad, debe ser estimado como una molestia. De manera que la restricción de una actividad no es la solución más adecuada para evitar los posibles daños por su realización, pues es mayor el daño que sufriría la sociedad por tal restricción, que el prejuicio se podría producir su realización (Coase, 1960).

Llevar la teoría de Ronald Coase a los terrenos de la responsabilidad por la actividad peligrosa de la conducción de vehículos y el seguro obligatorio, nos permite plantear que no es una solución adecuada restringir o prohibir la movilización vehicular con el objetivo de evitar un posible daño a la

\footnotetext{
${ }^{6}$ Es preciso establecer, que en este artículo se hace referencia a los daños compensatorios derivados de un accidente de tránsito. La figura jurídica de los daños compensatorios es distinta de los daños punitivos.

En la definición de daños punitivos Tobar (2011) establece que "en el derecho norteamericano los daños punitivos (punitive damages), han sido definidos por la Suprema Corte como "multas privadas impuestas por jurados civiles a fin de castigar conductas reprochables y para disuadir que se reiteren en el futuro" (p 157). Así los daños punitivos "son las sumas de dinero que los tribunales exigen pagar con el fin no de indemnización compensatoria, sino como una sanción con fines ejemplarizantes. (García \& Herrera, 2003, p203).
} 
víctima de un accidente de tránsito, porque tal restricción origina un daño mayor a la sociedad que los que acarrea la conducción de vehículos. En tal medida, la sociedad debe buscar herramientas legales para garantizar la reparación de los daños causados por la conducción de automotores y lograr un derecho eficiente en términos económicos.

A fin de evitar la restricción en el manejo de vehículos en beneficio de la sociedad, es necesario que, para garantizar la reparación de posibles daños derivados de un accidente vehicular, se exija mediante la ley un seguro obligatorio para todos los propietarios de vehículos. De manera que la sociedad compuesta por todos los dueños de los automotores, asuma la responsabilidad de posibles daños por la ejecución de la actividad.

\subsection{La Teoría de la Distribución del Riesgo}

Los postulados de la distribución del riesgo fueron planteados inicialmente por Gregory y Kalven (como se citó en Calabresis, 1961), estos autores desarrollaron que el criterio principal de la responsabilidad y del derecho de daños es la distribución del riesgo, considera "como uno de los problemas centrales de la teoría general de la reparación" (Ghersi, 1988, p31), especialmente en la construcción de la teoría de la responsabilidad aplicable a la conducción de vehículo, como actividad indispensable para suplir la necesidad diaria del hombre de transportarse de un lugar a otro. 
La distribución del riesgo entendida como la división del costo económico del daño, entre varios sujetos en un lapso de tiempo. De tal manera que "las pérdidas se soportan mejor si se fraccionan entre un gran número de individuos y se reparten a lo largo del tiempo" (Calabresi, 1984, p54).

Para la teoría de la distribución del riesgo, los accidentes de tránsito son de carácter rutinario, y en ellos no es procedente analizar las instituciones de dolo y culpa; lo esencial es reparar a la víctima, diluyendo el impacto económico del daño en la sociedad. Es precisamente la sociedad la que se considera como única responsable de los accidentes rutinarios producto de la utilización de un bien que le es útil para su desarrollo de la sociedad (Trazegnies, 2001). De este modo, el autor del daño no termina siendo víctima del sistema de responsabilidad desde el punto de vista económico, al pagar indemnizaciones cuantiosas que podrían empobrecerlo.

El anterior planteamiento, es un enfoque diferente al usualmente planteado de cara al problema de la responsabilidad por accidentes de tránsito. Que implica cambiar la búsqueda romanística del culpable, por la reparación de la víctima. Esto diferencia la tesis de la distribución del riesgo del sistema subjetivo y el objetivo de responsabilidad, en los cuales, una vez hallado el culpable o el responsable generador del riesgo, este debe pagar individualmente el valor del daño (Trazagnies, 2001).

La distribución del daño en los accidentes de tránsito es posible mediante el establecimiento de seguros (Trazagnies, 2001). Los que admiten una 
apropiada compensación de la víctima y un eficaz fraccionamiento de los perjuicios entre los asegurados mediante el pago de las primas ${ }^{7}$. Las que constituyen el fondo de cuantía suficiente, para sufragar los costos de los daños que se produzcan con ocasión a la materialización del siniestro (Martí, 2010).

El seguro se considera como un elemento para la socialización de los riesgos, de tal manera, que quién asume el costo de las indemnizaciones es la colectividad de los asegurados (Mantilla, 2004). Así reitera Mantilla, cuando el daño se produzca por un sujeto asegurado, la indemnización pasa de ser un problema de la víctima y del autor del daño a un asunto de repartición de riesgos asegurados (2004). Evento al que no se "habría podido llegar (...) si no fuera por la existencia y la posibilidad de distribuir socialmente los riesgos mediante el pago de primas de seguros (Corral, 2004, p. 398).

\subsubsection{Relación entre la teoría de la distribución del riesgo y el teorema de Coase}

Ambas teorías se complementan. La teoría de la distribución del riesgo, permite construir un sistema jurídico de responsabilidad eficiente en términos de Coase $^{8}$, que garantiza la indemnización a las víctimas de un

\footnotetext{
7 "La prima, es la contraprestación a cargo del tomador (costo del riesgo) y en favor de la aseguradora por el hecho de asumir el amparo frente a la ocurrencia de un determinado siniestro" (López, 2004, p.91). En este sentido manifiesta el Dr. David Echeverry que "la prima es el consto de la asunción del riesgo que depende a su vez de las tablas de probabilidad de su ocurrencia"

8"La delimitación inicial de los derechos legales tiene un efecto en la eficiencia con que opera el sistema económico. Un ordenamiento de los derechos puede ocasionar un valor mayor de la producción que
} 
accidente de tránsito de una forma ágil. Además, al distribuir el daño en la sociedad evita que los agentes dañadores sufran grandes pérdidas, con ocasión del pago de la indemnización.

La distribución permite una optimización y disminución en el costo de las transacciones en el mercado, pues al ser obligatoria la contratación del seguro, el costo de este contrato será bajo teniendo en cuenta que el Estado regula y vigila el cumplimiento de las condiciones contractuales. Lo que permite un mayor número de contratos de seguros y una reducción del valor de la prima, respecto del precio obtenido en el mercado a través de una negociación voluntaria.

De manera, que la teoría de la distribución del riesgo responde a un derecho eficiente que repara a las víctimas, responde a dinámicas propias de la industrialización de la sociedad, minimiza los costos del contrato de seguro.

\subsubsection{Diferencias entre la teoría de la distribución del riesgo y la teoría objetiva.}

Es preciso aclarar las diferencias entre la tesis objetiva y la distribución social del riesgo, en cuanto a la regulación de la conducción de vehículo.

cualquier otro. Pero si este arreglo de derechos no es establecido por el sistema legal, los costos de alcanzar el mismo resultado alterando y combinando los derechos a través del mercado pueden ser tan grandes que este arreglo óptimo de los derechos, y el mayor valor de la producción que ocasionaría, puede que nunca se logre" (Coase, 1960, p98). Así, cuando el Estado, en uso de sus facultades reglamentarias, impone la obligación de contratar un seguro para ejercer una actividad, limita un derecho legal, pero permite que el sistema económico opere de manera eficiente dada la reducción de costos. 
Diferencias que se centran en varios aspectos: primero el responsable del riesgo, segundo la exigencia de un contrato de seguro para su perfección, tercero el impacto económico, cuarto la exoneración de la responsabilidad y quinto el fraccionamiento de los costos de los daños ${ }^{9}$.

Primero, en cuanto al responsable del riesgo; la teoría objetiva considera como responsable el generador o beneficiario del riesgo, por su parte en la tesis de la distribución del riesgo no hay un responsable directo, pues la sociedad deberá asumir el daño en pro del bienestar común. Con tal que "no importa en quien recaiga el peso económico del daño, por que el mercado se encargará de distribuirlo" (Trazagnies 2001, p.84).

Segundo, en tanto a la exigencia de la reglamentación del contrato de seguro; la teoría objetiva, es indiferente de la existencia del contrato de seguro, son sus efectos los que motivan a los responsables a asegurarse, pues el propietario de un vehículo deberá responder de manera inexorable, con sus bienes, por los daños causado en un eventual accidente, razón por la cual se ven abocados a la contratación de un seguro, para que el riesgo sea asumido por la compañía aseguradora. A diferencia de la teoría de la distribución social del riesgo, en la cual la reglamentación y obligatoriedad del seguro es indispensable, esta teoría exige que el Estado regule como obligatorio el seguro a todos los propietarios de vehículos, con lo cual se

9 “El argumento al que la literatura jurídica actual suele recurrir con más frecuencia para justificar la imputación de los daños en función de criterios de responsabilidad sin culpa, es que las pérdidas se soportan mejor si se fraccionan entre un gran número de individuos y se reparten a lo largo del tiempo" (Calabresi, 1984, p 55). 
lograr la efectiva distribución del daño en la sociedad a un menor costos, debido qué todos los propietarios se encuentran asegurados (Trazagnies, 2001).

Tercero, en lo concerniente al impacto económico; la teoría de la distribución del dañoestá ligada a la obligatoriedad del seguro, y su exigencia es un requisito asociado a un costo operacional en el desarrollo de la actividad, necesario su ejercicio, los costos de las primas de seguro serán bajas, pues todo el parque automotor estará asegurado. Por el contrario, en la responsabilidad objetiva, al trasladar el daño, de un sujeto a otro, genera un impacto económico en el responsable, así el sistema objetivo, no reporta beneficios pues, sólo distribuye la responsabilidad mediante un proceso judicial, y una vez asignada los daños, estos no desaparecen, pero si aumentan los costos adicionales para las partes y el Estado, con la operación del aparato judicial (Papayannis, 2010).

Cuarto, la exoneración de la responsabilidad; en la teoría objetiva es posible la exoneración de la responsabilidad con la ruptura del nexo causal entre daño y víctima, a diferencia de la teoría de la distribución social del riesgo en la cual el daño no contempla la exoneración del daño, el que deberá ser asumido automáticamente con la sola ocurrencia del siniestro.

Quinto, en lo referente al fraccionamiento de los costos de los daños, el sistema de responsabilidad objetiva, estimula la contratación voluntaria del seguro lo que puede lograr una distribución eventual del daño, que depende 
de la voluntad de asegurarse del creador del riesgo. En cambio, en la teoría de la distribución del riesgo existe un fraccionamiento eficiente de los costos de los accidentes, pues el Estado al imponer el seguro obligatorio, todos los vehículos estarán asegurados y el daño será distribuido en la comunidad.

Si bien en el ordenamiento jurídico colombiano, no se hace alusión a la teoría de la distribución del riesgo, esta responde concretamente a la responsabilidad derivada de los daños corporales productos de un accidente de tránsito. Tal responsabilidad, aunque no lo establezca la norma, se determina en los postulados de la teoría de la distribución social del riesgo, teniendo en cuenta que los daños son fraccionados y asumidos por la sociedad, la indemnización opera de manera automática no se indaga por el culpable o el responsable, solo se repara lo que permite que el proceso de reclamación de los daños sea ágil, debido a que el Estado impone a todos los vehículos del país el seguro obligatorio de accidentes de tránsito SOAT.

\subsubsection{El Seguro obligatorio como medio de difusión del riesgo}

Para Calabresi, la función de la responsabilidad civil consiste en aminorar el costo de los accidentes a través de la reducción del número de accidentes mediante la prevención, la disminución de la pérdida con el fraccionamiento del costo de los daños y el reajuste de los costos administrativos derivados del tratamiento de los accidentes (1984). 
Por lo anterior, el contrato de seguro es parte esencial de la teoría de la distribución del riesgo pues, a través de este negocio jurídico se logra el fraccionamiento de los daños derivados de un accidente de tránsito, entre varios individuos, de lo que se obtiene un fondo que permite la indemnización de las víctimas, evento que cumple el fin principal de la responsabilidad civil.

Sin embargo, el fin del seguro en la teoría de la distribución no solo es reparar el daño a un bajo costo; sino disminuir los accidentes mediante la prevención resultante del estímulo financiero representado en el valor de la prima.

Para el caso de los accidentes automovilísticos, la prima, como incentivo para prevenir el daño, debe ser asumida por los propietarios de los automotores. Ellos están en mejores condiciones para controlar la actividad de la conducción y contribuir cómodamente y a un menor costo a fin de evitar el daño.

Este estimulo es "más notorio si las compañías de seguros establecen, como es usual primas diferenciadas en razón del riesgo y de las precauciones asumidas" (Trazegnies, 1999, p26). Por esta razón, "la existencia del seguro no puede admitirse como factor que relaje al asegurado en el cumplimiento de los deberes del presiniestro, con el manido, pero equívoco argumento de que para qué entonces está el seguro". (Jaramillo, 2013, p 276). De no 
existir el seguro, la conducción de vehículo sería una actividad ejecutada por debajo del costo.

En relación con la remoción de los costos de tipo administrativo derivados del tratamiento de los accidentes, el seguro disminuye los gastos administrativos en la contratación, debido a que la ley debe determinar y regular el contenido del contrato. A su vez, evita los gastos que implica un proceso judicial, pues la indemnización de los daños opera de manera automática.

\section{CONCLUSIONES}

El problema de investigación planteado al inicio de este artículo fue el siguiente: ¿la teoría de la culpa de corte romanista es adecuada para sustentar la responsabilidad derivada de la actividad riesgosa de conducción de vehículos?

De lo analizado a lo largo de este escrito, se concluye que la teoría de la culpa resulta inadecuada e insuficiente en la regulación de la responsabilidad derivada de la actividad riesgosa de conducción de vehículos. Lo anterior, por cuanto la culpa supone que el actor actuó con negligencia, aun cuando la responsabilidad derivada de la actividad 
peligrosa debe basarse en la potencial ocurrencia del daño derivado de la práctica de una actividad rutinaria.

Lo inadecuado de la teoría de la culpa salta a la vista haciendo exégesis de la jurisprudencia y doctrina vigentes.

\section{i. Seguimiento crítico de la tendencia jurisprudencial y doctrinal en Colombia}

En un seguimiento crítico de la evolución jurisprudencial, se observa que, en la exposición de la teoría de la responsabilidad derivada de la conducción, la Corte Suprema de Justicia sostiene la culpa como tesis mayoritaria. Sin embargo, trata sin distinción y tiende a confundir la presunción de la culpa y la presunción de la responsabilidad.

Así, la Corte Suprema de Justicia introduce la ruptura del nexo causal como única eximente de responsabilidad, aun cuando la presunción de culpa supone que el actor fue negligente. Si se aplicara la teoría de la culpa en debida forma, la eximente de responsabilidad estaría en que el sujeto que ejecuta la conducta demostrara que actuó con diligencia para desvirtuar la presunción. En otras palabras, la Corte Suprema introduce el nexo causal en los postulados de la culpa presunta con el fin de invertir la carga de la prueba y evitar imponer cargas innecesarias a la víctima. 
Aunado a lo anterior, la teoría del riesgo fue el fundamento de la primera sentencia en la que la Corte acogió la culpa presunta. De esta manera, la Corte no solo introdujo los postulados de la teoría del riesgo en el concepto de culpa presunta, sino que simultáneamente acogió la teoría del riesgo y de la falla en la guarda al indicar que la guarda y la culpa se complementaban.

Por su parte, el desarrollo doctrinal ha superado los postulados jurisprudenciales al entender que la culpa resulta insuficiente en la regulación de la responsabilidad en la conducción de automotores, para remplazarlos con la teoría del riesgo y la teoría de la distribución social del riesgo.

Con base en la doctrina más avanzada sobre la materia, en este trabajo se propone que, si bien la culpa es la base de la norma en la que se desarrolla la responsabilidad extracontractual en Colombia, la teoría clásica de la culpa es inocua para regular las exigencias de la sociedad motorizada y la responsabilidad en las actividades peligrosas.

No es dable, como hizo la Corte Suprema, tergiversar los fundamentos de una teoría a fin de ajustarla al contexto social, pues este proceso resulta impertinente para la compensación de las víctimas.

Si bien la sentencia con ponencia de William Namen del año 2009, la Corte Suprema adoptó los postulados objetivos, estos parecen haber sido descartados en jurisprudencia posterior. 
Por lo tanto, es preciso adoptar un cambio real y concreto en la norma (artículo 2356 C. C.) en cuanto a la teoría de la responsabilidad sobre la actividad rutinaria de la conducción. Si no se logra esta reforma legal, es menester que la jurisprudencia de las altas cortes oriente el desarrollo de legislación, de tal modo que el avance jurisprudencial dé cuenta de la teoría que mejor facilite elementos para la solución efectiva a los problemas jurídicos.

\section{ii. La teoría propuesta en esta investigación: La Distribución del Riesgo}

Para superar las dificultades teóricas que provienen de la jurisprudencia vigente en Colombia, la teoría propuesta desde este texto es la distribución social del riesgo.

Según esta teoría, en la regulación de la actividad rutinaria de la conducción, no se indaga por el responsable ni el generador del riesgo porque se considera que no existe responsabilidad directa, sino social. Para la teoría, la responsabilidad surge de un riesgo que debe ser asumido por la sociedad, constituida por todos los conductores de vehículos y no por cada conductor en cada accidente concreto.

Esta teoría se considera como la más adecuada en relación con la actividad de conducción de automotores puesto que cumple con varios objetivos: 
Primero, garantiza la indemnización de un daño, que se compensa con el fondo obtenido del pago de todas las primas. Dicha reparación, en todo caso, no será ilimitada y estará tasada en baremos.

Segundo, alcanza la eficiencia del derecho en la economía ya que, al requerir el Estado el seguro obligatorio a todos los propietarios de vehículos como un costo operacional del uso del bien, se disminuye el costo de las primas en el mercado. Este valor sería menor al que tendría que sufragar el actor en otro sistema de responsabilidad, en caso de verificarse el siniestro. En la Distribución Social del Riesgo, se fraccionan las pérdidas entre toda la sociedad asegurada.

Tercero, la teoría de distribución del riesgo, evita el empobrecimiento de un sujeto en particular ya que, ante el siniestro, responde el conjunto de los asociados y no se afecta de manera directa el peculio de un agente. Evitando que este, en un evento desafortunado, asuma costos que podrían superar su patrimonio.

Y, por último, se disminuyen los costos del proceso de reclamación, debido a que no se tendrá que acceder a la justicia ordinaria, descongestionando el sistema judicial. Solo se surtirá el trámite de reclamo ante la compañía aseguradora. 


\section{BIBLIOGRÁFIA}

ACCIARRI, H.; Barrero, A. \& Castellano, A. (2009) Seguro obligatorio de responsabilidad civil: Ensayo sobre instituciones en mercados imperfectos. Revista Estudios Económicos, vol.26, ( $\left.\mathrm{N}^{\circ} .52\right)$, pp. 1-27. Recuperado de http://bibliotecadigital.uns.edu.ar/scielo.php?script=sci_arttext\&pid=S0425$\underline{368 X 2009001100001}$

ACEDO, P. A. (2000) Derecho de los contratos: cuasicontratos y responsabilidad extracontractual. España: Dykinson.

AEDO, B. C. (2014) El problema del concepto de la culpa en la lex Aquilia: Una mirada funcional Vol. XXVII - $\mathrm{N}^{\circ}$ (1) pp 27-57. Recuperado de http://www.scielo.cl/pdf/revider/v27n1/art02.pdf

AJONA, A. M. y Rubio, M. (2002) Análisis económico del derecho. Precedente Revista Anuario Jurídico de la Facultad de Derecho y Ciencias Sociales de la Universidad ICESI, $\mathrm{N}^{\circ}$ (5) pp. 115- 150. Recuperado de https://www.icesi.edu.co/precedente/ediciones/2002/5AnaArjonaMauricioR ubio.pdf

ALESSANDRI, R. A. (1943) De la responsabilidad extracontractual en el derecho civil chileno. Santiago de Chile, Chile: Imprenta Universitaria.

ALONSO, S. R. (2000) (Responsabilidad civil y seguro. Anuario de la Facultad Derecho Universidad Autónoma de Madrid, No (4) pp. 193-204. Recuperado de https://www.uam.es/otros/afduam/pdf/4/Responsabilidad\%20civil\%20y\%2 0Seguro\%20Ricardo\%20Alonso\%20Soto.pdf 
AMATO, C.; Yong, S.; Castro, M.; Valencia, E.; Barbour, D. [y otros]. (2014). Reflexiones sobre la responsabilidad en el Siglo XXI. Bogotá: Editorial Politécnico Gran Colombiano.

ARAMBURO, C. M. (2008) Responsabilidad civil y riesgo en Colombia: apuntes para el desarrollo de la teoría del riesgo en el siglo XXI, Revista Facultad de Derecho y Ciencias Políticas, Vol. 38, ( $\left.{ }^{\circ} 108\right)$, pp.15-51. Recuperado de https://revistas.upb.edu.co/index.php/derecho/article/view/601/539

BAENA, A. F. (2010) Objetivación de la responsabilidad civil extracontractual en Colombia: tendencias, influencias y panorama (monografía de pregrado). Universidad EAFIT - Medellín. Recuperado de https://repository.eafit.edu.co/bitstream/handle/10784/458/Felisa_BaenaAr amburo_2010.pdf;jsessionid=D0BC0484769CF883ECF59827D3E8275D?s equence $=1$

CALABRESI, G. (1961) Some Thoughts on Risk Distribution and The Law $\begin{array}{llllll}\text { of Torts. Volumen } 70 & \mathrm{~N}^{\circ} & \text { (4) } & \text { pp. } & 499-552\end{array}$ http://digitalcommons.law.yale.edu/cgi/viewcontent.cgi?article=3035\&cont ext=fss_papers

CALABRESI, G. (1984). El coste de los accidentes análisis económico y jurídico de la responsabilidad civil. Barcelona, España: Ariel S.A.

CALABRESI, G. y Hirschoff, J. (2002) Hacia un test para determinar la responsabilidad objetiva en el sistema de responsabilidad civil extracontractual. THEMIS Revista de Derecho $\mathrm{N}^{\circ}$ (44), pp. 63 -82. Recuperado de https://dialnet.unirioja.es/servlet/articulo?codigo=5110299. 
CEBALLOS, M. R. (2006) La responsabilidad civil automovilística y el aseguramiento obligatorio y voluntario: un estudio en el Derecho colombiano y español. Cuadernos de Administración Universidad del Valle $\left(\mathrm{N}^{\circ} 35\right)$ Recuperado de http://bibliotecadigital.univalle.edu.co/xmlui/bitstream/handle/10893/2129/ La\%20responsabilidad\%20civil\%20automovilistica\%20\%207.pdf?sequenc $\underline{\mathrm{e}=1}$

COASE, R. (1960). El Problema del Costo Social. Traducción estudios públicos. recuperado de http://www.hacer.org/pdf/coase2.pdf

COASE, R. (2002) El análisis económico en Chicago. Themis Revista de Derecho $\mathrm{N}^{\circ}$ (44), pp.7-16. Recuperado de https://dialnet.unirioja.es/servlet/articulo?codigo $=5110295$

CORRAL T. H. (2004) Lecciones de responsabilidad civil extracontractual. Editorial Jurídica de Chile. Recuperado de https://filosofosinsentido.files.wordpress.com/2013/07/2176.pdf

COUSY, H. (2007) ¿El fin del seguro? Consideraciones sobre el seguro privado y sus fronteras Revista Foro Derecho Mercantil ( $\left.\mathrm{N}^{\circ}: 14\right)$ pp. 07-29

DIAZ-GRANADOS O. J. M. (2000). El seguro de responsabilidad 2a ed. Editorial Universidad del Rosario. Recuperado de http://www.ebrary.com

DÍEZ-PICAZO P. L. (2000). Culpa y riesgo en la responsabilidad civil extracontractual. Anuario de la Facultad Derecho Universidad Autónoma de Madrid, $\quad\left(\mathrm{N}^{\circ} 4\right) \quad$ pp. 153-166 Recuperado de http://www.uam.es/otros/afduam/pdf/4/culpa\%20y\%20riesgo\%20en\%20la \%20responsabilidad\%20civil.pdf 
DOMÍNGUEZ A R. (2001) Aspectos de la relación de causalidad en la responsabilidad civil con especial referencia al derecho chileno. Revista de Derecho Universidad de Concepción N²09. Recuperado de www.revistadederecho.com/pdf.php?id=2978

FASECOLDA (2014) Análisis técnico y económico del ramo de automóviles. Recuperado

de http://www.fasecolda.com/files/8514/2749/0713/Anlisis_tcnico_y_econmic o_del_ramo_de_automviles_-_2014_v.2.pdf

FERNÁNDEZ, C. A. \& Salvador P. C. (2006). Causalidad y responsabilidad, INDRET Revista para el Análisis del Derecho. Recuperado de http://www.indret.com/pdf/329_es.pdf

GARCÍA, M. \& Herrera, L (2003) El concepto de los daños punitivos o punitive damages. Revista Estudios Socio-Jurídicos, 5(1): 211-229Bogotá (Colombia).

Recuperado dehttps://revistas.urosario.edu.co/index.php/sociojuridicos/article/view/88

GHERSI C. A. (1998) La transferencia del riesgo y los nuevos daños sociales no reparables Revista Jurídica de la Universidad de Palermo. $\mathrm{N}^{\circ}$ (1) pp.31-44 Recuperado de http://www.palermo.edu/derecho/publicaciones/pdfs/revista_juridica/n3N1Abril1998/031Juridica03.pdf

GÓMEZ, P. F. (2000). Coches y accidentes (II): algunos problemas del seguro de responsabilidad civil del automóvil. INDRET Revista para el Análisis del Derecho $\left(\mathrm{N}^{\circ} 03\right)$ Recuperado de http://www.indret.com/pdf/024_es.pdf 
GÓMEZ, P. F. (2001) Carga de la Prueba y Responsabilidad Objetiva, INDRET Revista para el Análisis del Derecho. Recuperado de http://www.indret.com/pdf/040_es.pdf

GONZÁLEZ, O. S. (2012) Seguro obligatorio de responsabilidad civil en España: 1996-2011(Tesis de pregrado). Facultad de Ciencias Económicas y Empresariales Universidad de León. España. Recuperado de https://buleria.unileon.es/bitstream/handle/10612/1878/71433458N_GADE JULIO12.pdf?sequence=1.

KOCH, B. A. (2003) La labor del European Group on Tort Law. La cuestión de la "Responsabilidad Objetiva". Indret Revista para el Análisis del Derecho. $\left(\mathrm{N}^{\circ} 2\right)$ Barcelona. Recuperado de http://www.indret.com/pdf/129_es.pdf

JARAMILLO, C. I. (2013). Los deberes de evitar y mitigar el daño. Editorial

Temis S.A

LASHERAS, S. A. (1963) Costes y tarificación del seguro obligatorio de responsabilidad civil de vehículos de motor. Recuperado de https://www.fundacionmapfre.org/documentacion/publico/i18n/catalogo_im agenes/imagen_id.cmd?idImagen $=1062265$

LÓPEZ-BREA, L. D. R. J. (2010). El intervencionismo público en los seguros privados. Tesis Doctoral. Universidad Nacional de Educación a Distancia. España. Recuperado de https://dialnet.unirioja.es/servlet/tesis?codigo=24091 
LÓPEZ-BREA, L. D. R. J. (2013). Estudio y clasificación de los seguros privados desde la perspectiva del derecho administrativo. España: Editorial Tirant Lo Blanch. Recuperado de http://www.ebrary.com

LÓPEZ, M. D. (2006) El derecho de los jueces, obligatoriedad del precedente constitucional, análisis de sentencias y líneas jurisprudenciales y teoría del derecho judicial. Editorial LEGIS

MANTILLA, E. F. (2004) La norma de indemnización de perjuicios causados por las actividades peligrosas OPINIÓN JURÍDICA vol. 3, No. 6 pp. 101-126 Recuperado de http://revistas.udem.edu.co/index.php/opinion/issue/view/118

MANTILLA, E. F. (2007). El principio general de responsabilidad por culpa del derecho privado colombiano, Opinión Jurídica - Universidad de Medellín, Vol. 6, (No. 11), pp. 129 - 15. Recuperado de http://revistas.udem.edu.co/index.php/opinion/article/view/144/128

MARCOS, C. M. (2000). La Ley de las XII Tablas. Revista de filología clásica y hebrea, Tomo 51, ( $\mathrm{N}^{\mathrm{o}}$ 155), 353-383. Recuperado de http://summa.upsa.es/pdf.vm?id=0000003623\&page=1\&search=\&lang=es

MARTÍ, S. N. (2010) Actividad aseguradora y contrato de seguro. Revista Derecho y Cambio Social $\mathrm{N}^{\circ}$ (22) pp1-39 recuperado de http://www.derechoycabiosocial.com/revista022/contrato_de_seguro.pdf

MARTÍN, C. M. (2005) Una primera aproximación a los "Principios de Derecho europeo de la responsabilidad civil". Indret Revista para el Análisis del Derecho. ( $\left.\mathrm{N}^{\circ} 284\right)$ de http://www.indret.com/pdf/284_es.pdf 
MARTÍN-CASALS, M. (2011) La Modernización del Derecho de la Responsabilidad Extracontractual. Coruña, España: Universidad de Murcia Publicaciones.

MARTÍNEZ, C. (2009) Maximización de la riqueza y asignación de derechos en Richard Posner. Persona y Derecho, $\mathrm{N}^{\circ}$ (60) pp.323-351. Recuperado de http://dadun.unav.edu/bitstream/10171/17551/1/43641651.pdf

MARTÍNEZ, R. G. (1998) Responsabilidad civil extracontractual. Bogotá, Colombia. TEMIS S.A

MERCADO N. E. (1988) Fundamentos del sistema de responsabilidad civil extracontractual. Revista Thémis $\mathrm{N}^{\circ}$ (10) pp. 70-73 Recuperado de https://dialnet.unirioja.es/descarga/articulo/5110118.pd

PAPAYANNIS, D. (2010) Sobre los límites de la responsabilidad objetiva Recuperado de https://www.udg.edu/Portals/123/curriculums/2002279/Sobre\%20los\%201 \%C3\%ADmites\%20de\%20la\%20responsabilidad\%20objetiva.pdf

PAPAYANNIS D. M. (2009) El enfoque económico del Derecho de daños. DOXA $\quad N^{\circ} \quad$ (32) pp. 459-495 Recuperado de https://www.udg.edu/Portals/123/curriculums/2002279/el-enfoqueeconomico-del-derecho-de-danos.pdf

PEIRANO, F. J (2004) Responsabilidad Extracontractual. Bogotá, Colombia. 
POSNER, R. (2002) El Movimiento Del Análisis Económico Del Derecho: Desde Bentham Hasta Becker. Themis Revista de Derecho N (44), pp.3754. Recuperado de https://dialnet.unirioja.es/servlet/articulo?codigo $=5110297$

POSNER, R. A. (S. F.) Maximización de la Riqueza y Tort Law: Una Investigación Filosófica Recuperado

de http://www.eumed.net/cursecon/textos/posner-tort.pdf

RAMOS, P. R. (2008) De la Responsabilidad Extracontractual. Santiago de Chile, Chile: Fondo de Publicaciones de la Facultad de Ciencias Jurídicas y Sociales de la Universidad de Concepción.

ROSENKRANTZ, C. F. (2006) En defensa de la responsabilidad estricta una revisión crítica del tratado de responsabilidad extracontractual, de Enrique Barros Bourie. Editorial Jurídica de Chile. Recuperado de http:// www.cepchile.cl/cep/site/artic/20160304/asocfile/20160304094743/r112_cr osenkrantz_Resposabilidad-Estricta.pdf

SALAS, C. A. (2013) Principios de Derecho Europeo de la Responsabilidad Civil. Revista de la Asociación Española de Abogados Especializados en Responsabilidad Civil y Seguro, ISSN-e 1887-7001, No. 48, 2013, págs. 916. Recuperado https://dialnet.unirioja.es/servlet/articulo?codigo $=4729415$

SANTOS, B. J. (2006) Instituciones de Responsabilidad Civil Tomo III. Bogotá, Colombia: Pontificia Universidad Javeriana

SANZ E. A.(2000) El Concepto Jurídico de Responsabilidad en la Teoría General del Derecho, Anuario de la Facultad Derecho Universidad Autónoma de Madrid, ( $\left.{ }^{\circ} 4\right)$ pp27-56 Recuperado de https://www.uam.es/otros/afduam/pdf/4/Elconceptojuridicoderesponsabilida denlaTeoriaGeneraldelDerecho.pdf 
SCHIPANI, S. (2007). De la Ley Aquilia a Digesto 9. Perspectivas sistemáticas del Derecho romano y problemas de la responsabilidad extracontractual. Revista de Derecho Privado, núm. 12-13, pp. 263-287. Recuperado de http://www.redalyc.org/pdf/4175/417537588009.pdf

SPECTOR, H. (2003) Justicia y bienestar desde una perspectiva de derecho comparado. DOXA $\mathrm{N}^{\circ}$ (26). Recuperado de https://www.researchgate.net/publication/39678088_Justicia_y_bienestar_d esde_una_perspectiva_de_derecho_comparado

TABORDA, C. L. (2000) Responsabilidad Civil Extracontractual. Academia de la Magistratura, Lima. Recuperado de http://sistemas.amag.edu.pe/publicaciones/dere_civil_proce_civil/resposab_ civil_extracontra.pdf

TAMAYO, L. A. (2005). La responsabilidad civil extracontractual y la contractual. Ediciones Doctrina y Ley LTDA. Bogotá - Colombia

TAPIA, R. M. (2007) El contrato de seguro y el exceso de responsabilidad civil. Revista del Magister y Doctorado en Derecho $N^{\circ}$ (1) pp. 159-200 Recuperado de http://www.revistas.uchile.cl/index.php/RMDD/issue/view/1609

TAPIA, R. M. (2007) Responsabilidad asegurable en el derecho chileno Revista Chilena de Derecho Privado, $\mathrm{N}^{\circ}$ (9) pp. 73-92. Recuperado de http://www.redalyc.org/pdf/3708/370838867003.pdf

TOBAR, T. J. A, (2011) Los daños punitivos y las oportunidades de aplicación en Colombia. Revista Republicana, No. 11, pp. 155-167. 
Recuperado de http://revista.urepublicana.edu.co/wpcontent/uploads/2012/07/Los-da\%C3\%B1os-punitivos-y-las-oportunidadesde-aplicacion-en-Colombia.pdf

TRAZEGNIES, G. F. (1999) La Responsabilidad Extracontractual Tomo I Editorial TEMIS S.A.

TRAZEGNIES, G. F. (2001) La Responsabilidad Extracontractual Tomo II Vol. IV Fondo Editorial Pontificia Universidad Católica del Perú.

VELÁSQUEZ, P. O. (2009). Responsabilidad civil extracontractual. Colombia: Universidad de La Sabana. Recuperado de http://www.ebrary.composads

VELÁSQUEZ, P. O. C. (2013) Responsabilidad civil extracontractual. Bogotá, Colombia: Editorial TEMIS S.A.

VELÁSQUEZ, P. O (2015) Responsabilidad civil extracontractual. Bogotá. Colombia: Editorial TEMIS S. A.

\section{JURISPRUDENCIA Y NORMAS CITADAS}

Código Civil de Colombia.Ley 84 de 1873. Recuperado de http://www.secretariasenado.gov.co/senado/basedoc/codigo_civil.html

Código Civil de Perú. Decreto Legislativo 295 del 1984. Recuperado de https://andrescusi.files.wordpress.com/2016/07/cc3b3digo-civilperuan_edicion-2016.pdf 
Corte Suprema de Justicia de Colombia, Sentencia de 14 de marzo de 1938 del Magistrado Ponente Ricardo Hinestroza Daza.

Corte Suprema de Justicia de Colombia, Sentencia de 31 de mayo de 1938 del Magistrado Ponente Libardo Escallón.

Corte Suprema de Justicia de Colombia, Sentencia de 18 de mayo de 1972 del Magistrado Ponente Ernensto Gamboa

Corte Suprema de Justicia de Colombia, Sentencia de 04 junio de 1.992 del Magistrado Ponente Carlos Esteban Jaramillo Schloss.

Corte Suprema de Justicia de Colombia, Sentencia de 27 de febrero 1998 del Magistrado Ponente Rafael Romero Sierra

Corte Suprema de Justicia de Colombia, Sentencia de 06de mayo 1998 del Magistrado Ponente Rafael Romero Sierra

Corte Suprema de Justicia de Colombia, Sentencia de 05 de mayo de 1999. Magistrado Jorge Antonio Castillo Rúgeles, 
Corte Suprema de Justicia de Colombia, Sentencia de 22 de agosto de 2000. Magistrado Ponente Jorge Santos Ballesteros.

Corte Suprema de Justicia de Colombia, Sentencia de 24 de agosto de 2009. Magistrado Ponente William Namén Vargas.

Corte Suprema de Justicia de Colombia, Sentencia de 01 de junio de 2010. Magistrado PonenteArturo Solarte Rodríguez.

Corte Suprema de Justicia de Colombia, Sentencia de 18 de diciembre de 2012. Magistrado Ponente Ariel Salazar Ramírez.

Corte Suprema de Justicia de Colombia, Sentencia de 08 de abril de 2014. Magistrado Ponente Fernando Giraldo Gutiérrez.

Corte Suprema de Justicia de Colombia, Sentencia de 06 de mayo de 2016. Magistrado Ponente Luis Armando Tolosa Villabona.

Principios de derecho europeo de la responsabilidad civil. Recuperado de http://civil.udg.edu/php/biblioteca/items/298/PETLSpanish.pdf 